\title{
Predicting Undergraduate Leadership Student Goal Orientation Using Personality Traits
}

\author{
Kevan W. Lamm, Ph.D. \\ President \\ LR Brand, Inc. \\ Emana Sheikh \\ University of Florida \\ Hannah S. Carter, Ph.D. \\ Associate Professor Department of Agricultural Education and Communication \\ Director Wedgworth Leadership Institute for Agriculture and Natural Resources \\ University of Florida \\ Alexa J. Lamm, Ph.D. \\ Assistant Professor Department of Agricultural Education and Communication \\ Associate Director UF/IFAS Center for Public Issues Education \\ University of Florida
}

\begin{abstract}
Finding strategies to increase the motivation of students, their connection with the material, and retention of the content, has been very important within leadership education. Previous research studies have shown that personality traits can predict desired outcomes, including goal orientation or motivational disposition. However, there have not been any studies which have specifically analyzed how personality predicts goal orientation in undergraduate leadership students. The results of this study found that between $15 \%$ and $28 \%$ of the variance in goal orientation dispositions was predicted by personality factors, confirming the predictive nature of the relationship. Based on the observed results leadership educators are recommended to include personality and goal orientation discussions into their leadership curriculum and to create a learning environment that accommodates all learners.
\end{abstract}

\section{Introduction}

According to Hofer (2011) "few topics concern teachers at all levels as much as the motivation of students" (p. 140). Finding strategies to increase the motivation of students and in turn their connection with the material and retention of the content has been of paramount importance within leadership education (e.g. Buckmaster \& Carroll, 2009; Lamm, Carter, \& Melendez, 2014a; Rosch, 2015; Schwarz-McCotter, 2008). However, within an undergraduate leadership education context few empirical studies have examined the motivational dispositions of this population, along with the antecedents and predictors of such inclinations (Lamm et al., 2014a). 
From a leadership development perspective an emergent theme in the literature has been the psychodynamic approach, or an acknowledgement that personality underlies many of the outward manifestations that are perceived as behavior (Stech, 2013). Specifically, personality represents "a consistent pattern of ways of thinking, feeling, and acting with regard to the environment, including other people" (Stech, 2013, p. 319). Consequently, personality has been established as one of the most widely recognized predictors of behavior within organizations and educational environments (Bass, 2008).

However, despite the acknowledgement of personality as relevant factor to consider when engaging in leadership development (Northouse, 2013), little empirical research has been conducted to link this persistent set of traits to undergraduate student outcomes, particularly motivation (Lamm, Carter, Stedman, Lamm, 2014b). One possible explanation for the lack of research within this area is the large array of personality traits and measures available in the literature base, "there are thousands of personality measures in the published literature" (Hogan \& Roberts, 2001, p. 6). Accordingly, the abundance of choice may represent an impediment to establishing an accessible framework to properly study learner motivation though a personality lens (Iyengar \& Lepper, 2000).

Another limitation of past studies has been considering personality traits as individual entities and thus measuring and treating personality variables as individual factors (Lamm et al, 2014b). Human behavior represents a dynamic environment where multiple personality factors are interacting in a dynamic system constantly interacting with the external environment (Hampson, 2012). Focusing on single traits, particularly in a dynamic classroom educational environment, may limit the utility of findings, especially from a motivational perspective (Barrick, Mount, \& Judge, 2001). However, a more comprehensive analysis of personality characteristics within a population of undergraduate leadership students may provide valuable audience insights as well as the ability to leverage those insights to help inform motivational strategies, specifically, addressing the need for future research "studying the antecedents of intrinsic motivation [in undergraduate leadership students]" (Lamm et al., 2014a, p. 112) within the literature.

Although the literature contains numerous articles describing the motivation of students (e.g. Aarnio, Nieminen, Pyörälä, \& Lindblom-Ylänne, 2010; Kember, Ho, \& Hong, 2008; Turner \& Herren, 1997), these studies have tended to focus on broad recommendations rather than acknowledging the nuance and personal nature of motivation at the learner level. Research focused on a proximal set of variables, such as personality, and linking these variable to individual learner motivation dispositions may provide valuable insights to an educator(Hofer 2011; Stech, 2013).

Previous research linking student motivational dispositions, or goal orientation, to personality has indicated a likely relationship. For example, past studies have shown personality antecedents have been shown to predict motivational tendencies in organizational settings (Payne, Youngcourt, \& Beaubien, 2007). Additionally, Steinmayer, Bipp and Spinath (2011) found that goal orientation, in combination with personality, was a predictor of academic achievement in a sample of 11th and 12th graders beyond the predictive capacity of intelligence alone. However, there remains a gap in the literature focused on leadership education specifically 
examining the personality and goal orientation dispositions of this population of learners.

According to the National Leadership Education Research Agenda 2013 - 2018 priority area one identifies the need to "explore the role of the individual learner in leadership education" (Andenoro et al., 2013, p. 5). This research was conducted to provide insights regarding the individual differences in personality and motivational disposition of undergraduate students within a leadership education setting.

\section{Theoretical Framework}

The theoretical framework for the study is based on the Five Factor Model (FFM) of personality (Norman, 1963) and the conceptualization of goal orientation proposed by Vandewalle (1997).

The Five-Factor Model of Personality. The five-factor model serves as a consensual organization of traits. The purpose behind the model has been to create a structured set of personality factors to be utilized as an organized inventory of the more than 15,000 personalitytrait adjectives in the English language (Goldberg, 1990). Although alternative models of personality exist (Block, 1995; Eysenck, 1992), the Big Five personality traits model proposed by Costa and McCrae (1992) has been shown to be reliable and appropriate for analysis based on an extensive use within the literature (e.g. Judge, Simon, Hurst, \& Kelley, 2014).

The personality factors of openness, conscientiousness, extraversion, agreeableness, and neuroticism comprise the Big Five model (Costa \& McCrae, 1985; Costa \& McCrae, 1992). Openness has been described as "imaginative, cultured, curious, original, broad-minded, intelligent, and artistically sensitive (Barrick \& Mount, 1991, p. 5). Conscientiousness has been described by an orientation towards dependability, organization, and responsibility (Costa \& McCrae, 1992). Extraversion, or surgency, has been associated with traits such as "being sociable, gregarious, assertive, talkative, and active" (Barrick \& Mount, 1991, p. 3). Agreeableness has been defined by "being courteous, flexible, trusting, good-natured, cooperative, forgiving, soft-hearted, and tolerant" (Barrick \& Mount, 1991, p. 4). The final factor, neuroticism or conversely emotional stability, has been conceived to include "being anxious, depressed, angry, embarrassed, emotional, worried, and insecure" (Barrick \& Mount, 1991, p. 4).

Goal Orientation. Goal orientation has been demonstrated to be important because it has provided a mental framework to interpret situations and respond to those situations (Dweck, 1991). Dweck (1986) and later Dweck and Legget (1998) theorized that people have goal orientation differences according to their personality traits. Goal orientation has been conceptualized as tending to occur within two domains, in particular, either learning goal orientation or performance goal orientation. Individuals with learning goal orientation have tended to view their ability as malleable. They hold goals to further develop their ability rather than a desire to demonstrate their current level of ability (Vandewalle, 1997). Conversely, individuals holding performance goal orientation view their ability as fixed and difficult to develop. Consequently goals are set to validate their static abilities (Vandewalle, 1997). 
Vandewalle (1997) extended upon the work of Dweck (1986) and suggested goal orientation might be further conceptualized as a three-factor construct. In particular performance goal orientation was partitioned into two distinct dimensions, either performance goal avoid (avoiding negative judgments) or performance goal prove (gaining positive judgments) (Vandewalle, 1997). The multi-dimensional nature of performance goal orientation was derived from the human response to desire to gain positive judgment and avoid negative judgments of one's ability (Heyman \& Dweck, 1992).

Goal orientation has represented a likely channel through which to understand learner motivational dispositions (Hofer, 2011), in particular, the use of either mastery or performance goals or motives (Ames, 1992). Accordingly, "students who adopt mastery goals are those whose primary desire is to understand and master the material. By contrast, students with performance goals are more likely to focus on their achievement relative to the performance others" (Hofer, 2011, p. 144). From this perspective learners that have a mastery orientation might be considered to be more learning goal orientated (LGO) stemming from one's desire to acquire new skills, master new situations, and improve competence in order to develop the self (Vandewalle, 1997). Alternatively, performance goals might be categorized as either performance prove goal orientation (PGOP) motivated by one's desire to prove ability in order to gain positive judgments (Vandewalle, 1997), or performance avoid goal orientation (PGOA) motivated by one's desire to avoid negative judgments on their ability and disproving of their competence (Vandewalle, 1997).

Personality Predicting Goal Orientation. Previous research has established the relationship between personality and goal orientation. For example, Culbertson, Leiva, Henning, and Post-Piller (2009) examined the relationship between personality, goal orientation, and job preferences. The results indicated both personality and goal orientation were relevant considerations in a model seeking to represent job preference in undergraduate students. Additionally, LGO had a statistically significant relationship with conscientiousness, agreeableness, and extraversion; PGOP had a statistically significant negative relationship with emotional stability; and PGOA had a statistically significant negative relationship with agreeableness, extraversion, emotional stability, and openness.

Although the personality and goal orientation results observed by Culbertson et al. (2009) were statistically significant the findings were inconsistent with previous research. For example, Bipp, Steinmayr, and Spinath, (2008) examined the relationship between personality, goal orientation, and intelligence within a sample of university students. Bipp et al. (2008) found statistically significant relationships between personality and goal orientation. However, unlike Culbertson et al. (2009) LGO had statistically significant relationships with extraversion, openness, and agreeableness while PGOA had statistically significant negative relationships with emotional stability and extraversion. Within both studies PGOP had a statistically significant negative relationship with emotional stability.

In their meta-analysis of goal orientation studies Payne et al. (2007) conceptualized personality as an antecedent for goal orientation disposition consistent with the suggestions of Dweck (1986) and Dweck and Legget (1998). In particular, goal orientation dispositions may represent compound traits composed of multiple personality factors (Hough \& Schneider, 1996). 
Illuminating the nature of the relationship from a comprehensive personality perspective may therefore provide incremental validity beyond the bi-variate correlations found previously thus providing educators greater insight regarding the best way to motivate learners based on a combination of personality and goal orientation considerations (Payne et al., 2007).

\section{Purpose \& Research Questions}

The purpose of this study was to examine how undergraduate leadership students' personality predicted their goal orientation. The study was driven by the following research objectives:

1. Describe the personality characteristics of undergraduate leadership students using the five-factor model of personality.

2. Describe the goal orientation characteristics of undergraduate leadership students.

3. Identify the relationship between personality and goal orientation in undergraduate leadership students.

4. Identify how personality predicts goal orientation in undergraduate leadership students.

\section{Methods}

The population for this study was undergraduate leadership students. A descriptive and correlational research design was employed to address the research objectives. A census of four classes of undergraduate leadership students from two leadership courses in a single southern land grant university was included in the study. The first course was an upper level offering directed at group and team leadership. Data from course one were collected in the spring of 2013 $(n=32)$, the spring of $2014(n=44)$, and the spring of $2015(n=40)$. The second course was an upper level course directed at personal leadership development. Data from the second course were collected in the spring of $2013(n=61)$. Multiple classes were studied to increase generalizability of results (Ary, Jacobs, \& Sorensen, 2010). A total of 177 responses were obtained and represented a $97 \%$ response rate. Respondents received no compensation or course credit for participating in the study.

Demographic data were obtained through respondent self-report. The sample was 34.5\% $(n=61)$ male and $63.8 \%(n=113)$ female. Respondents represented all undergraduate classifications within the university, 3.4\% $(n=6)$ freshman, $12.4 \%(n=22)$ sophomore, $37.3 \%$ $(n=66)$ junior, $45.2 \%(n=80)$ senior, with one individual indicating they were a graduate student.

Participant race and ethnicity were defined as self-perceived membership in population groups that define themselves by cultural heritage, language, physical appearance, behavior, or other characteristics ("Standards", 1995, p. 26). In this study, race was defined as: American Indian or Alaska native; Asian or Pacific Islander; Black or African American; White; or Other. Ethnicity was defined as either Hispanic/Latino(a)/Chicano(a) or not. These categories were based on United States of America Office of Management and Budget standards for the classification of Federal Data on Race and Ethnicity ("Standards", 1995, p. 29). From an ethnicity perspective 10.7\% $(n=19)$ of respondents identified themselves as 
Hispanic/Latino(a)/Chicano(a). In regard to respondents' race, 80.8\% $(n=143)$ identified themselves as White, $8.5 \%(n=15)$ identified themselves as Black or African American, $7.9 \%(n$ $=14)$ identified themselves as Asian or Pacific Islander, 0.6\% $(n=1)$ identified themselves as American Indian or Alaska native. Additionally, seven individuals identified themselves within an 'Other' category.

A paper-based questionnaire composed of previously developed, valid and reliable instruments was used to collect participant responses. Using previously established measures has been shown to increase observed data validity and reliability (Ary et al., 2010). The questionnaire was reviewed by a panel of experts knowledgeable in survey design, personality, and undergraduate instruction for face and content validity prior to administration.

Respondent personality was measured using the IPIP-NEO, specifically the version developed by Johnson (2011). Individuals responded to 44 personality statements indicating their response on a five-point, Likert-type scale. Possible responses to each item included: 1 Strongly Disagree, 2 -Disagree, 3 - Neutral, 4 -Agree, 5 - Strongly Agree. The measure was based on the International Personality Item Pool (IPIP) established by Goldberg et al. (2006). The measure was selected based on reliability characteristics with coefficient alpha values greater than .70 previously observed for each facet construct (Johnson, 2011). Based on established social science research standards, a Cronbach's $\alpha$ of .70 or greater is considered sufficient (Cortina, 1993; Schmitt, 1996; Streiner, 2003). Specifically, the emotional stability index was found to have a Cronbach's $\alpha$ of .78, the conscientiousness index was found to have a Cronbach's $\alpha$ of .71, the agreeableness index was found to have a Cronbach's $\alpha$ of .83, the extraversion index was found to have a Cronbach's $\alpha$ of .84, and the openness index was found to have a Cronbach's $\alpha$ of .70.

Respondent goal orientation was measured using the work domain goal orientation instrument developed by Vandewalle (1997). Individuals responded to 13 goal orientation statements indicating their response on a five-point, Likert-type scale. Possible responses to each item included: 1 - Strongly Disagree, 2 - Disagree, 3 - Neutral, 4 - Agree, 5 - Strongly Agree. The learning goal orientation index was found to have a Cronbach's $\alpha$ of .82, the performance goal orientation prove index was found to have a Cronbach's $\alpha$ of .81 , and the performance goal orientation avoid index was found to have a Cronbach's $\alpha$ of .84 .

Results were analyzed using SPSS version 22. Descriptive statistics were calculated to determine the personality and goal orientation preferences of respondents. Pearson productmoment correlations were calculated to examine the relationship between variables and simultaneous multiple regression was calculated to examine the predictive capacity between variables (Ary et al., 2010). Thresholds for statistical significance had an a priori alpha level set at .05 .

\section{Results}

Personality. Respondent personality scores were calculated using the IPIP-NEO scoring key. IPIP-NEO agreeableness scale scores are based on a one to five scale. Respondents had the highest mean score in agreeableness $(M=3.86, S D=.39)$ and the lowest mean score in 
extraversion $(M=3.59, S D=.72)$. The mean, standard deviation, minimum, and maximum scores for each personality factor (emotional stability, conscientiousness, agreeableness, extraversion, and openness) are presented in Table 1.

Table 1.

Personality Scale Scores

\begin{tabular}{lccccc} 
Personality Scale Scores & $n$ & $M$ & $S D$ & Min & Max \\
\hline & & & & & \\
Agreeableness & 164 & 3.86 & 0.39 & 2.50 & 4.63 \\
Openness & 173 & 3.80 & 0.60 & 2.20 & 5.00 \\
Emotional Stability & 171 & 3.74 & 0.68 & 1.40 & 5.00 \\
Conscientiousness & 174 & 3.74 & 0.61 & 2.00 & 5.00 \\
Extraversion & 175 & 3.59 & 0.72 & 1.20 & 5.00 \\
\hline
\end{tabular}

Goal Orientation. Respondent goal orientation scores were calculated using the Vandevalle (1997) work domain goal orientation instrument scoring key. Goal orientation scale scores are based on a one to five scale. Respondents had the highest mean score in learning goal orientation $(M=3.99, S D=.56)$ and the lowest mean score in performance goal avoid orientation $(M=2.65, S D=.78)$. The mean, standard deviation, minimum, and maximum scores for each goal orientation index are presented in Table 2.

Table 2.

Goal Orientation Scale Scores

\begin{tabular}{lccccc} 
Goal Orientation Scale Scores & $n$ & $M$ & $S D$ & Min & Max \\
\hline & & & & & \\
Learning Goal Orientation & 175 & 3.99 & 0.56 & 2.60 & 5.00 \\
Performance Goal Orientation - Prove & 174 & 3.70 & 0.74 & 1.50 & 5.00 \\
Performance Goal Orientation - Avoid & 173 & 2.65 & 0.78 & 1.00 & 4.75 \\
\hline
\end{tabular}

Relationships between Personality and Goal Orientation. Pearson product-moment correlations between personality and goal orientation were completed to investigate the nature of the relationship between variables (Ary et al., 2010). Correlation coefficients and statistical significance between variables are provided in Table 3. Correlations ranged from negligible to moderate in magnitude (Davis, 1971). Learning goal orientation had a statistically significant relationship with all personality factors, with the exception of agreeableness. Performance goal prove orientation had a statistically significant negative relationship with agreeableness and a statistically significant positive relationship with extraversion. Finally, performance goal avoid orientation had a statistically significant negative relationships with all personality factors with the exception of conscientiousness. 
Table 3.

Intercorrelations between Personality and Goal Orientation

$\begin{array}{llll}1 & 2 & 3 & 4\end{array}$

$5 \quad 6$

$\begin{array}{lll}6 & 7 & 8\end{array}$

1. Emotional Stability

2. Conscientiousness

$-$

3. Agreeableness

$.22 * *-$

4. Extraversion

$.28 * * .36 * * \quad-$

5. Openness

$.42 * * \quad .15 \quad .13$

6. Learning Goal

$.11 \quad .15 * \quad .17 *$

$.26 * *$

$.32 * * \quad .10$

Orientation

7. Performance Goal

.05

.08

$-.26 * *$

$36 * *$

Orientation - Prove

8. Performance Goal

$\begin{array}{ll}-.21 * * & -.07\end{array}$

$-.22 *$

$.24 * * \quad .41 * * \quad-$

Orientation - Avoid

$* p<.05, * * p<.01$

Personality Predicting Goal Orientation. Multiple regression analysis was completed to determine whether a predictive relationship existed between the five personality factors and each of the three goal orientations. Goal orientation was treated as a dependent variable. The five personality factors were treated as the independent variables of interest.

Unstandardized regression coefficients in the form of variable level effects along with statistical significance for the learning goal orientation model are provided in Table 4. According to the analysis $28 \%$ of the variance in learning goal orientation is explained by the five factors of personality, and this explained variance is statistically significantly different from 0 because the omnibus model is statistically significant $\left(R^{2}=.28, F(5,153)=8.52, p<.000\right)$. The personality factors of emotional stability, conscientiousness, and openness were found to be statistically significant predictors when controlling for all five personality factors.

Table 4.

\section{Predicted Impact of Personality Factors on Learning Goal Orientation}

\begin{tabular}{lcc}
\hline & $b$ & $p$ \\
\hline Constant & 1.67 & $.000^{* * *}$ \\
Emotional Stability & 0.20 & $.003^{* *}$ \\
Conscientiousness & 0.23 & $.002^{* *}$ \\
Agreeableness & -0.15 & .182 \\
Extraversion & -0.03 & .684 \\
Openness & 0.37 & $.000^{* * *}$ \\
\hline
\end{tabular}

Note. ${ }^{* * *} p<.001,{ }^{* * p}<.01, R^{2}=.28$ 
Unstandardized regression coefficients in the form of variable level effects along with statistical significance for the performance goal-prove orientation model are provided in Table 5 . According to the analysis $20 \%$ of the variance in learning goal orientation is explained by the five factors of personality, and this explained variance is statistically significantly different from 0 because the omnibus model is statistically significant $\left(R^{2}=.20, F(5,152)=7.65, p<.000\right)$. The personality factors of conscientiousness and extraversion were found to be statistically significant positive predictors and agreeableness was found to be a statistically significant negative predictor when controlling for all five personality factors.

Table 5.

Predicted Impact of Personality Factors on Performance Goal - Prove Orientation

\begin{tabular}{lrl}
\hline & $b$ & $p$ \\
\hline Constant & 4.38 & $.000^{* * *}$ \\
Emotional Stability & -0.05 & .529 \\
Conscientiousness & 0.24 & $.014^{*}$ \\
Agreeableness & -0.66 & $.000^{* * *}$ \\
Extraversion & 0.35 & $.000^{* * *}$ \\
Openness & -0.02 & .858 \\
\hline
\end{tabular}

Note. ${ }^{* * *} p<.001, * p<.05, R^{2}=.20$

Unstandardized regression coefficients in the form of variable level effects along with statistical significance for the performance goal-avoid orientation model are provided in Table 6 . According to the analysis $15 \%$ of the variance in learning goal orientation is explained by the five factors of personality, and this explained variance is statistically significantly different from 0 because the omnibus model is statistically significant $\left(R^{2}=.15, F(5,152)=5.37, p<.000\right)$. The personality factors of agreeableness, extraversion, and openness were found to be statistically significant negative predictors when controlling for all five personality factors.

Table 6.

Predicted Impact of Personality Factors on Performance Goal - Avoid Orientation

\begin{tabular}{lrl}
\hline & $b$ & $p$ \\
\hline Constant & 5.53 & $.000^{* * *}$ \\
Emotional Stability & -0.03 & .772 \\
Conscientiousness & 0.10 & .370 \\
Agreeableness & -0.37 & $.024^{*}$ \\
Extraversion & -0.20 & $.043^{*}$ \\
Openness & -0.26 & $.022^{*}$ \\
\hline
\end{tabular}

Note. ${ }^{*} p<.05, R^{2}=.15$ 


\section{Conclusions, Implications, and Recommendations}

The results associated with this study are noteworthy for their contribution to both leadership education theory and practice. Although the data from the study are only applicable to the study respondents, from a practical perspective a number of quantitative benchmarks have been established that may help to provide undergraduate leadership student profile insights to educators based on the research sample within the broader population. Additionally, an ancillary benefit of the research included the validation of rigorous, free, and easily administered instruments available to gather undergraduate leadership student personality and goal orientation disposition data.

Overall, the sample of undergraduate leadership students included in the study indicated relatively high, and similar, levels of openness, conscientiousness, extraversion, agreeableness, and emotional stability. However, the range of scores observed indicate the need for educators to be prepared to work with a wide diversity of student personality dispositions (McKeachie \& Svinicki, 2013). A limitation of the present study is the relatively small sample size, and associated limitations on generalizability of results. Although steps were taken to minimize any potential bias associated with the sample any implications or recommendations should be considered within the known limitations of the research (Ary et al., 2010). Nevertheless, an implication from these results is that leadership educators should be flexible in their approach and sensitive to the needs of individual students. Developing skills as an educator to detect differences in introversion and extraversion, agreeableness, openness, conscientiousness, and emotional stability is critical to providing a meaningful learning environment for students (McKeachie \& Svinicki, 2013)

The differences between goal orientation dispositions are also noteworthy. The lowest score was reported on the PGOA disposition. These results would indicate that the students in the sample tend to be most motivated by their desire to seek mastery over a subject matter, in this leadership research. However, a close secondary motivation to prove their competence in the material should also inform classroom motivational strategies. The lower PGOA value indicated that students are not motivated by their fear of being perceived as incompetent. For example, students may be more inclined to participate in classroom activities or discussions if they are passionate about the material, or have a desire to show how much they know more so than out of fear of being called on and not knowing the answer.

Based on the goal orientation results a recommendation would be that leadership educators working with undergraduate leadership students represented by the research sample work to develop a more mastery, or LGO, learning environment. Providing a supportive environment for learners where intellectual risk taking is encouraged should result in more learner motivation. Allowing learners to revise and improve their writing, grading based on criteria rather than relative to other learners (on a curve), providing constructive feedback, and dropping test questions that are missed by a significant proportion of learners are suggested approaches to align an undergraduate leadership classroom environment with the LGO results observed (Hofer, 2011). According to Hofer (2011) an LGO classroom discussion is visible when "students ask genuine questions to which they do not already know the answers, driven by a desire to better understand the material, rather than to impress their peers and the instructor" (p. 
144). Future research is suggested to better identify the specific teaching tactics and approaches preferred by learners according to their goal orientation disposition.

An additional recommendation for leadership educators working with undergraduate leadership students represented by the research sample would be to become proficient with PGOP classroom strategies. For example, allowing for opportunities for students to actively share their experiences and insights through directive questions intended to elicit a specific response. Additionally, using assessment methodologies that balances the opportunity toexplore responses, such as open-ended essay questions for LGO students balanced with multiple choice, matching, or fill in the blank approaches for PGOP students (McKeachie \& Svinicki, 2013). Finally, educators are recommended to minimize PGOA motivation when possible. For example, calling on students that do not know the correct answer with the intent of embarrassing them in front of their peers as a means to motivate them to learn may have the opposite motivational effect if learner self-efficacy is diminished (Stajkovic \& Luthans, 1998).

From a theoretical perspective, the nature, and directionality, of the relationships between each personality factor and goal orientation disposition was explored through Pearson productmoment correlations (Ary et al., 2010). The results indicated LGO had a statistically significantly positive relationship to all personality factors with the exception of agreeableness. These results were unlike those of Bipp et al. (2008) that found non-significant relationships with emotional stability and conscientiousness as well as Culberston et al. (2009) that also found a nonsignificant relationship with emotional stability. PGOP orientation had a statistically significant negative relationship with agreeableness and a positive relationship with extraversion. Findings were again inconsistent with Bipp et al. (2008) and Culbertson et al. (2009) where a statistically significant negative relationship with emotional stability was observed. PGOA had a statistically significant negative relationship with all personality factors with the exception of conscientiousness. These results were similar to those of Culberston et al. (2009) that reported statistically significant negative relationships across all personality factors. However, Bipp et al. (2008) observed statistically significant negative relationships within emotional stability and extraversion. An implication from the diversity of results relative to previous research is that the nature of the relationship between personality and goal orientation dispositions, particularly within a student population, is unclear. Future research with larger sample sizes representing a diversity of instructional content areas is recommended.

Extending beyond replication of previous study correlational analysis the results of the present study indicated that between $15 \%$ and $28 \%$ of the variance in goal orientation disposition was predicted by the Big-Five personality factors. These results confirmed the suggestion posed by Hough and Schneider (1996), specifically, goal orientation dispositions are compound traits composed of multiple personality factors. Table 7 summaries the directionality of the statistically significant personality predictors for each goal orientation disposition. 
Table 7.

Summary of Statistically Significant Personality Predictors of Goal Orientation Dispositions

\begin{tabular}{lccc}
\hline & LGO & PGO-P & PGO-A \\
\hline Emotional Stability & + & N/A & N/A \\
Conscientiousness & + & + & N/A \\
Agreeableness & N/A & - & - \\
Extraversion & N/A & + & - \\
Openness & + & N/A & - \\
\hline
\end{tabular}

It is essential that students of all personalities be accommodated with a learning curriculum that best fits their needs (McKeachie \& Svinicki, 2013), consequently the results of this study indicate it may also be helpful for educators to create a curriculum that interweaves aspects of all goal orientations to best fit the five personality factors. For example, PGOP had an observed a relationship with extraversion. Within a classroom of undergraduate leadership students working in a leadership group project, it may be useful for educators to motivate more extraverted group members with not only the possibility of an A, but through successfully completing experiential learning opportunities that require more social and outgoing interfacing with peers. Conversely, more introverted, or agreeable, students can be accommodated for by providing a dedicated time for quiet reflection that does not require the need to demonstrate their competence in the material.

Future research is recommended to fully explore how personality and goal orientation may also serve to predict differential student outcomes such as performance or satisfaction, either at a project or class level. For example, effects of different styled curriculums based on personality and goal orientation to predict student selected goals may provide further information in the area of study. Through a better understanding of personality on goal orientation, leadership educators are better able to create and provide an effective curriculum that students will not only excel academically in but also gain experiences that serve as learned lessons for future application.

If leadership educators allocate time to engage students in meaningful conversations around the effects of personality on processing and creating goals, it may help to further gain increased student engagement. Even if certain learning styles and personality factors are not applicable to all, personality discussion allows students to view their capabilities and goals with more clarity (Lamm et al., 2014b). For example, previous studies suggest that classroom goal orientation styles may influence the patterns of adaptive motivation when goals for mastery are salient and fully adopted and understood by students regardless of dispositional antecedents (Ames \& Archer, 1988). Improved engagement and attention, may in turn assist undergraduate students to attain higher levels of performance within various learning environments through a more meaningful connection with the material. 


\section{References}

Aarnio, M., Nieminen, J., Pyörälä, E., \& Lindblom-Ylänne, S. (2010). Motivating medical students to learn teamwork skills. Medical Teacher, 32(4), e199-e199.

doi:10.3109/01421591003657469

Ames, C. (1992). Classrooms: Goals, structures, and student motivation. Journal of educational psychology, 84(3), 261-271.

Ames, C., \& Archer, J. (1988). Achievement goals in the classroom: Students' learning strategies and motivation processes. Journal of educational psychology, 80(3), 260.

Andenoro, A. C., Allen, S. J., Haber-Curran, P., Jenkins, D. M., Sowcik, M., Dugan, J. P., \&

Osteen, L. (2013). National Leadership Education research agenda 2013-2018:

Providing strategic direction for the field of leadership education. Retrieved from Association of Leadership Educators website: http://leadershipeducators.org/ ResearchAgenda.

Ary, D., Jacobs, L. C., \& Sorensen, C. (2010). Introduction to research in education. Belmont, CA: Wadsworth Cengage Learning.

Barrick, M. R., \& Mount, M. K. (1991). The Big Five personality dimensions and job performance: A meta-analysis. Personnel Psychology. 44, 1-26.

Barrick, M. R., Mount, M. K., \& Judge, T. A. (2001). Personality and performance at the beginning of the new millennium: What do we know and where do we go

next?. International Journal of Selection and assessment, 9(1-2), 9-30.

Bass, B. M. (2008). The bass handbook of leadership. New York, NY: Free Press.

Bipp, T., Steinmayr, R., \& Spinath, B. (2008). Personality and achievement motivation:

Relationship among big five domain and face scales, achievement goals, and intelligence.

Personality and Individual Differences, 44(7), 1454-1464, doi: 10.1016/j.paid.2008.01.001.

Block, J. (1995). A contrarian view of the five-factor approach to person-ality description. Psychological Bulletin, 117, 187-215.

Buckmaster, D. R., \& Carroll, N. J. (2009). Motivating students--factors to consider. (teaching Tips/Notes). NACTA Journal, 53(2), 53.

Cortina, J. M. (1993). What is coefficient alpha? an examination of theory and applications. Journal of Applied Psychology, 78(1), 98-104. doi:10.1037/0021-9010.78.1.98

Costa, P. T., \& McCrae, R. R. (1985). The NEO personality inventory: Manual, form S andform $R$. Psychological Assessment Resources. 
Costa, P. T., Jr, \& McCrae, R. R. (1992). Revised NEO personality inventory and five factor inventory professional manual. Odessa, FL; Psychological Assessment Resources.

Culbertson, S. S., Leiva, P. I., Henning, J. B, \& Pos-Priller, S. (2009). The Role of Personality and Goal Orientation in Student Preferences for Job Attributes. Canadian Journal of Career Development, 8(1), 39-49.

Davis, J. A. (1971). Elementary survey analysis. Englewood Cliffs, NJ: Prentice-Hall.

Dweck, C.S. (1986). Motivational processes affecting learning. American Psychologist, 41, 1040-1048.

Dweck, C. S. (1991, January). Self-theories and goals: Their role in motivation, personality, and development. In Nebraska symposium on motivation (Vol. 38, No. 3, pp. 199-235). Lincoln, NE: University of Nebraska Press.

Dweck, C.S., \& Leggett, E. L. (1998). A social-cognitive approach to motivation and personality. Psychological Review, 95, 256-273.

Eysenck, H. J. (1992). Four ways five factors are not basic. Personality and Individual Differences, 13, 667-673.

Goldberg, L. R., Johnson, J. A., Eber, H. W., Hogan, R., Ashton, M. C., Cloninger, C. R., \& Gough, H. C. (2006). The international personality item pool and the future of publicdomain personality measures. Journal of Research in Personality, 40, 84-96.

Goldberg, L. R. (1990). An alternative "description of personality": The Big-Five factor structure. Journal of Personality and Social Psychology, 59, 1216-1229.

Hampson, S. E. (2012). Personality processes: Mechanisms by which personality traits "get outside the skin". Annual review of psychology, 63, 315-330. doi:10.1146/annurev-psych120710-100419.

Heyman, G. D., \& Dweck, C. S. (1992). Achievement goals and intrinsic motivation: Their relation and their role in adaptive motivation. Motivation and Emotion, 16, 231-247.

Hofer, B. (2011). Motivation in the College Classroom. In W. McKeachie, \& M. Svinicki (Eds.), McKeachie's Teaching Tips (pp. 140-150). Cengage Learning.

Hogan, R., \& Roberts, B. W. (2001). Personality and industrial and organizational psychology. In B. W. Roberts \& R. Hogan (Eds.), Personality psychology in the workplace (pp. 3-16). Washington, DC: American Psychological Association.

Hough, L. M., \& Schneider, R. J. (1996). Personality traits, taxonomies, and applications in organizations. In K. R. Murphy (Ed.) Individual differences and behavior in organizations (pp. 31-88). San Francisco: Jossey-Bass. 
Iyengar, S. S., \& Lepper, M. R. (2000). When choice is demotivating: Can one desire too much of a good thing?. Journal of personality and social psychology, 79(6), 995-1006.

Johnson, J. A. (2011). Development of a short form of the IPIP-NEO personality inventory. Poster Presented at the 2nd Biennial Meeting of the Association for Research in Personality, Riverside, CA.

Judge, T. A., Simon, L. S., Hurst, C., \& Kelley, K. (2014). What I experienced yesterday is who I am today: Relationship of work motivations and behaviors to within-individual variation in the five-factor model of personality. Journal of Applied Psychology, 99(2), 199-221. doi: $10.1037 / \mathrm{a} 0034485$

Kember, D., Ho, A., \& Hong, C. (2008). The importance of establishing relevance in motivating student learning. Active Learning in Higher Education, 9(3), 249-263. doi:10.1177/1469787408095849

Lamm, K. W., Carter, H. S., \& Melendez, M. W. (2014a). Investigating the linkage between intrinsic motivation and project team satisfaction in undergraduate leadership students. Journal of Agricultural Education. 55(3), 103-115. doi: 10.5032/jae.2014.03103

Lamm, K. W., Carter, H. S., Stedman N. L. P. \& Lamm, A. J. (2014b). Teaching transformational leadership to undergraduate agricultural leadership students: using the personality trait of agreeableness to improve understanding. Journal of Agricultural Education. 55(4), 24-37. doi: 10.5032/jae.2014.04024

McKeachie, W., \& Svinicki, M. (2013). McKeachie’s teaching tips. Cengage Learning.

Norman, W. T. (1963). Toward an adequate taxonomy of personality attributes: Replicated factor structure in peer nomination personality ratings. The Journal of Abnormal and Social Psychology, 66(6), 574-583. doi:10.1037/h0040291

Northouse, P. G. (2013). Leadership: Theory and practice (6th ed.). Thousand Oaks: Sage Publications.

Payne, S. C., Youngcourt, S. S., \& Beaubien, J. M. (2007). A meta-analytic examination of the goal orientation nomological net. Journal of Applied Psychology, 92(1), 128-150. doi: 10.1037/0021-9010.92.1.128

Rosch, D. (2015). Effects of classroom-based team experiences on undergraduate student leadership development: when practice does not make perfect. Journal of Leadership Education, 14(3), 104-118. doi: 1012806/V14/I3/R7

Schmitt, N. (1996). Uses and abuses of coefficient alpha. Psychological Assessment, 8(4), 350353. doi:10.1037/1040-3590.8.4.350 
Schwarz-McCotter, S. (2008). What do they need? intrinsic motivation and online leadership learning. Journal of Leadership Education, 7(1), 92-115.

Stech E. L. (2013). Psychodynamic Approach. In P. G. Northouse (Ed.), Leadership: Theory and practice (6th ed.) (pp. 319-348). Thousand Oaks: Sage Publications.

Stajkovic, A. D., \& Luthans, F. (1998). Self-efficacy and work-related performance: A metaanalysis. Psychological bulletin, 124(2), 240-261.

Standards for the classification of federal data on race and ethnicity. (1995). Retrieved June 13, 2013, from http://www.whitehouse.gov/omb/fedreg_race-ethnicity/

Streiner, D. L. (2003). Starting at the beginning: An introduction to coefficient alpha and internal consistency. Journal of Personality Assessment, 80(1), 99-103.

doi:10.1207/S15327752JPA8001_18

Steinmayr, R., Bipp, T., \& Spinath, B. (2011). Goal orientations predict academic performance beyond intelligence and personality. Learning and Individual Differences, 21(2), 196-200.

Turner, J., \& Herren, R. V. (1997). Motivational needs of students enrolled in agricultural education programs in georgia. Journal of Agricultural Education, 38(4), 30-41. doi:10.5032/jae.1997.04030

Vandewalle, D (1997). Development and Validation of a Work Domain Goal Orientation Instrument. Educational and Psychological Measurement, 57, 995-1015.

\section{Author Biographies}

Kevan Lamm, Ph.D., is the president of LR Brand, Inc. a private consulting firm specializing in evaluation, operational execution, and talent development.

Emana Sheikh, is an undergraduate student at the University of Florida.

Alexa Lamm, Ph.D., is an assistant professor in the Department of Agricultural Education and Communication and Associate Director of the UF/IFAS Center for Public Issues Education at the University of Florida.

Hannah Carter, Ph.D., is an associate professor of leadership education in the Department of Agricultural Education and Communication at the University of Florida. Within this appointment, she is the Director of the Wedgworth Leadership Institute for Agriculture and Natural Resources and also the interim director for the UF/IFAS Center for Leadership. 